\title{
3rd Thymus Workshop: Rolduc 1991
}

Long before the European Council of Ministers put Maastricht on the map, scientists researching into the mysteries of the thymus had discovered and enjoyed the excellent secluded facilities provided by the Centrum Rolduc in the 12th century monastery nearby. The 3rd Thymus Workshop was attended by approximately 100 participants who gathered together for 3 days of informal but intensive presentations and discussions of current research data.

The meeting opened with a guest lecture from Dr. Mike Owen (London) who spoke on the "Regulation of gene expression during T cell differentiation and activation"; a topic that admirably set the scene for the Workshop sessions that followed, since an understanding of gene regulation should ultimately provide the meeting point for the many and varied current areas of thymus research. Such areas include the sequential steps through which $\mathrm{T}$ cells pass during their intrathymic development, the way in which these steps are controlled via signals provided by the stromal cells of the thymic microenvironment (e.g. epithelial cells, dendritic cells and macrophages), and the perturbation of these processes in disease states.

Contributors to these sessions were encouraged to submit manuscripts, based on their presentation, for publication in Developmental Immunology, subject to normal reviewing procedures. It is these papers that are now collected together in this special 'Rolduc' volume. Although it is difficult to reproduce in the written word the highly charged atmosphere of a stimulating scientific meeting, we hope that this volume will provide the reader with a more detailed presentation of the research work discussed while at the same time giving a little of the atmosphere enjoyed by the participants.

Mary A. Ritter 


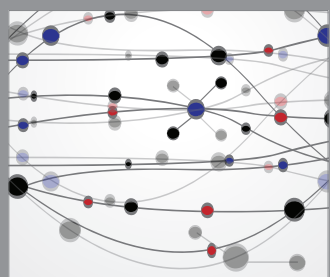

The Scientific World Journal
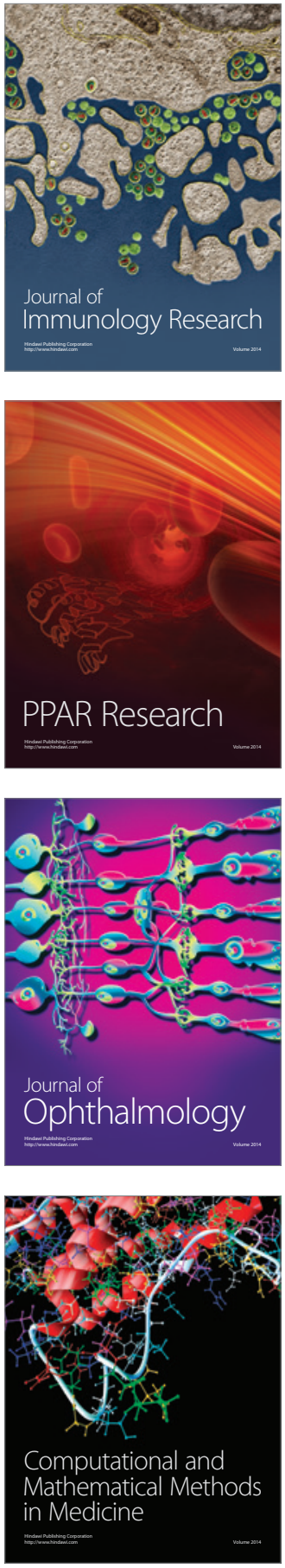

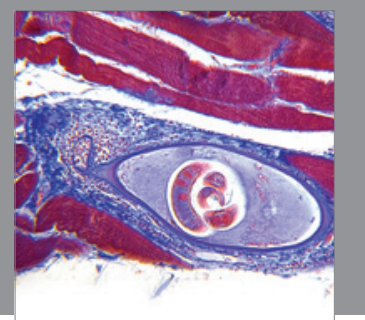

Gastroenterology

Research and Practice
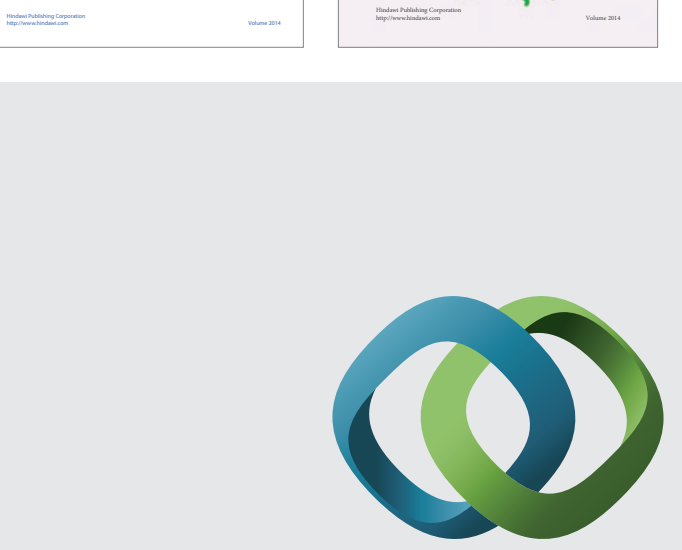

\section{Hindawi}

Submit your manuscripts at

http://www.hindawi.com
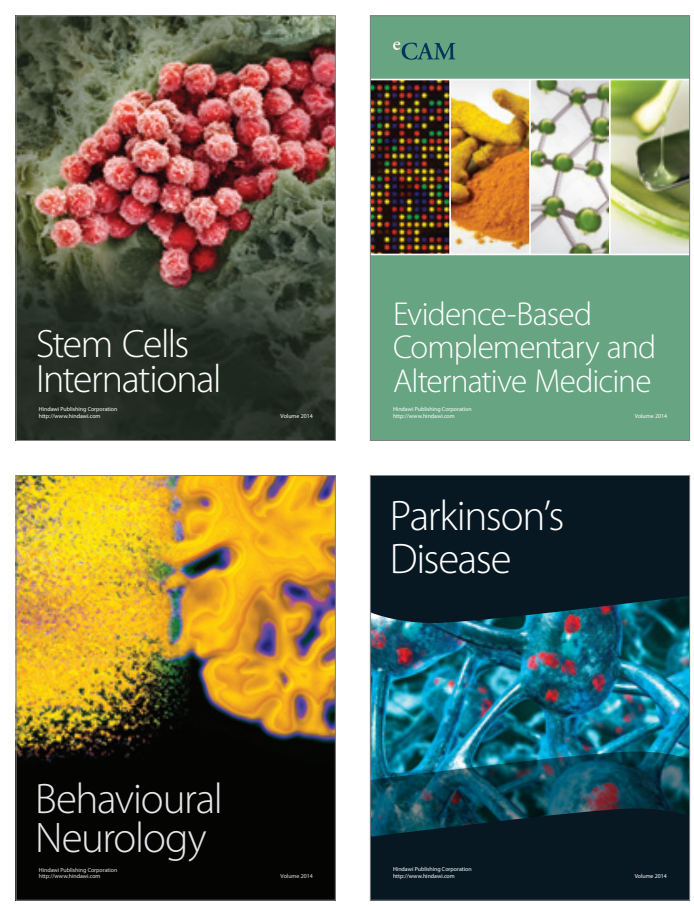

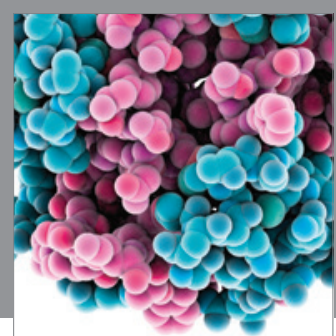

Journal of
Diabetes Research

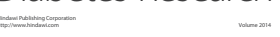

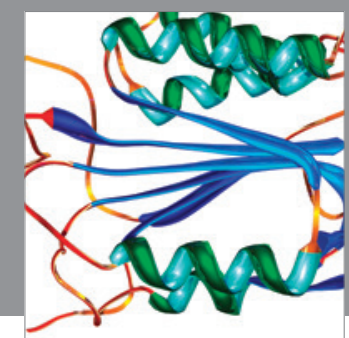

Disease Markers
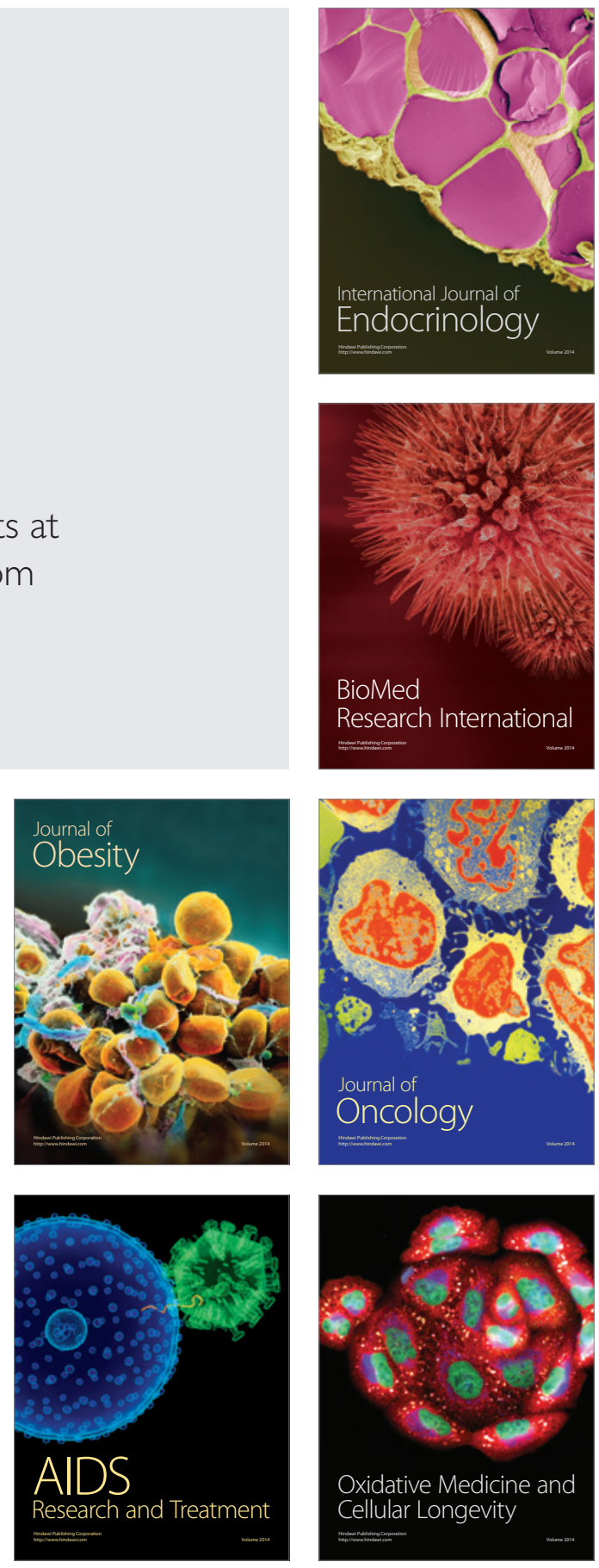